\title{
CURE OF EUNECTES NOTAEUS (Cope) FROM AMOEBIASIS
}

\author{
by
}

\author{
E. F. JACOB I \\ Artis, Amsterdam
}

Entamoeba invadens RoDHAIN is known as a dangerous parasite in reptiles, especially snakes and lizards. Up till now it has mostly been found in specimens which are kept in captivity. When these are carriers they show no signs of disease, but the faeces contain cysts and can infect healthy reptiles. If the reptiles are ill, the symptoms mostly are serious. They begin with a loss of appetite and an increasing need for drinking water. Within a few weeks the faeces merely consist of bloody mucus, containing a large number of hystolytic forms as well as a few cysts of Entamoeba invadens. In the case of Lacerta agilis (STAM, 1958), the animals died on an average within 25 days from inoculation (14 to 34 days). Different species of Natrix which had been infected died in 13 to 77 days from the onset of infection (RATCLIFFe and Geiman, 1938). Barrow and Stockton (1960) found that the temperature affected the symptoms in infected snakes. When the animals were kept at $13^{\circ} \mathrm{C}$ there were no internal pathological changes within two to six weeks but at $25^{\circ} \mathrm{C}$ these were very clear.

These changes, as described by different authors, are ulcers of the colon. In experiments nearly the entire colon is damaged to such an extent that no individual ulcers can be distinguished. Ulcers may also be found in the ilium. The liver may have one or several abscesses. Inflammation sometimes spreads from the gut to the kidneys.

The disease may be spread by the cysts from the faeces. These cysts are highly sensitive to desiccation (Hill and Neal, 1954), so that we may suspect water of being the main source of infection. The transport of cysts from one cage to another by insects such as cockroaches may be possible but has not yet been proved as far as I am aware. A very simple, but effective way of cleaning an infected cage is to let it dry out thoroughly for several days.

The old method of finding carriers by microscope checks of the excrements for amoebic cysts has proved to be not trustworthy. Most times, these are absent. Only a faecal culture is a safe method (FIENNEs, 1959).

At the University of Utrecht (Veterinary Department), where our samples are checked, the following method is used. About 0.25 grammes of faeces are inoculated on Locke egg serum ${ }^{1}$ and one knife point of sterile rice starch is added. Four test tubes are prepared and 3, 4, 5 and 6 drops of penicillinstreptomycine solution ${ }^{2}$ are added to reduce bacterial growth. If 10 days after inoculation, at $25^{\circ}$ $27^{\circ} \mathrm{C}$, no amoebae are present, the result is assumed to be negative. As this method has in our case only been used since 1959, all other checks mentioned below are only microscope examinations for cysts or hystolitic forms.

On May 14th, 1955 cysts of Entamoeba invadens were found in droppings of one of the snakes in a terrarium in our reptile house, containing specimens of Constrictor constrictor (LinnaEus) and Eunectes murinus (LinNaEus). Other faecal samples from the same cage were negative. As all snakes seemed to be in perfect health, no steps were taken. That on July 17th, 1956 and also later, excrement samples of the same snake (identified by a typical combination of different worm eggs) proved negative is, as we know now, of no importance.

Although not proved, the 24 Constrictor constrictor,

1) Four fresh eggs (sterilized with alcohol 96\%) mixed with $50 \mathrm{~cm}^{3}$ Locke Solution. Let test tubes coagulate during two to three hours at $70^{\circ}$ to $80^{\circ} \mathrm{C}$.

Locke Solution: $100 \mathrm{~cm}^{3}$ aqua destillata, 0.9 grammes $\mathrm{NaCl}, 0.06$ grammes $\mathrm{KCl}, 0.02$ grammes $\mathrm{CaCl}_{2}, 0.02$ grammes $\mathrm{Na}_{2} \mathrm{CO}_{3}, 0.1$ gramme glucose. Afterwards, a mixture of Locke Solution with inactivated horse serum 7 to 1 is added.

2) To $20 \mathrm{~cm}^{3}$ sterile Ringers Solution 1 gramme of streptomycine and 100.000 I.U. of penicillin are added. 
born in the night of 10th/11th November, 1955 in this cage are most likely to have come in contact with infected faeces. The young snakes were removed in the morning and housed in another terrarium. They developed very satisfactorily. We gave away twelve specimens and kept twelve. Some of the snakes, we presented, died shortly afterwards, but we do not know how many. Nine out of our twelve died in the period between March 4th and May 24th, 1956 from amoebiasis. The research (STAM, 1958) made it highly probable that all were infected at the same time. As we isolated the snakes as soon as infection was proved, three stayed free from the illness and are still alive today.

In the same cage, where the babies were born, a Eunectes notaeus (COPE) was placed on October 10th, 1957. In the meantime, some of the snakes had died, but there had been no case of amoebiasis. Regular dropping checks (again only microscope examinations) had always been negative.

On October 22nd and on November 5th, 1958 a specimen of E. murinus died from amoebiasis. On November 1st our $E$. notaeus was apparently ill. The droppings with blood and mucus were checked on November 4th and found to contain Entamoeba invadens. On November 5th, mucus mixed with blood was found in the cage. From November 7th onward, the snake was placed in a higher temperature, viz. $25^{\circ}-29^{\circ} \mathrm{C}$. As it ate two rats on November 19th, we thought there might be a chance of curing it. As an experiment chloroquine, a very mild drug in human practice, was chosen. The dose was based on 5 milligrammes to 100 grammes body weight for the first two days and 2.5 milligrammes for the next twelve. So from November 22nd for two days 100 milligrammes and for twelve days 50 milligrammes, dissolved in water, were administered, by means of a rubber tube to which a funnel had been fixed. Even during this treatment, the snake ate two Golden Hamsters on November 30th.

On November 26th, after five days of treatment, a microscope examination of the excrements was already negative. After the treatment, the snake ate normally and seemed in excellent health. Only the urine was reddish, even till January 12th, 1959. On July 17th, 1959 cultures showed a positive result and we decided to repeat the treatment. Before we did so (already some months later), samples of the faeces were tested again, but no more positive results could be obtained. Up till now, it has not been possible to test the drug in other cases of amoebiasis as none have occurred since in our reptile house.

Only in one case of a suspected, but not proved infection with another (unknown) Amoeba, a Natrix sipedon and two young Varanus (salvator and indicus) were given the same treatment with chloroquine. The Natrix and the $V$. salvator refused to take any food during and after the treatment and died. Only the $V$. indicus started eating again, after a short period of forced feeding.

\section{REFERENCES}

Barnow, J. H., Stockton, J. J., 1960: The influence of temperature on the host-parasite relationship of several species of snakes infected with Entamoeba invadens. J. of Protozool., 7, p 379.

FienNes, R. N. T-W-, 1959: Report of the Society's Pathologist for the year 1957. Proc. Zool. Soc. Lond., Vol. 132 , p. 129.

Hinl, W. C. O. \& Neal, R. A., 1954: An epizootic due to Entamoeba invadens at the Gardens of the Zoological
Society of London. Proc. Zool. Soc. London, Vol. 123, p. 731.

Ratcliffe, H. L. \& Genman, Q. M., 1938: Spontaneous and experimental amebic infection in reptiles. Arch. Path. 25, p. 160.

Stam, A. B., 1958: The relationship between Entamoeba invadens Rodhain and its hosts. Thesis. (Laboratorium voor Parasitologie der Rijksuniversiteit te Leiden, Holland; 


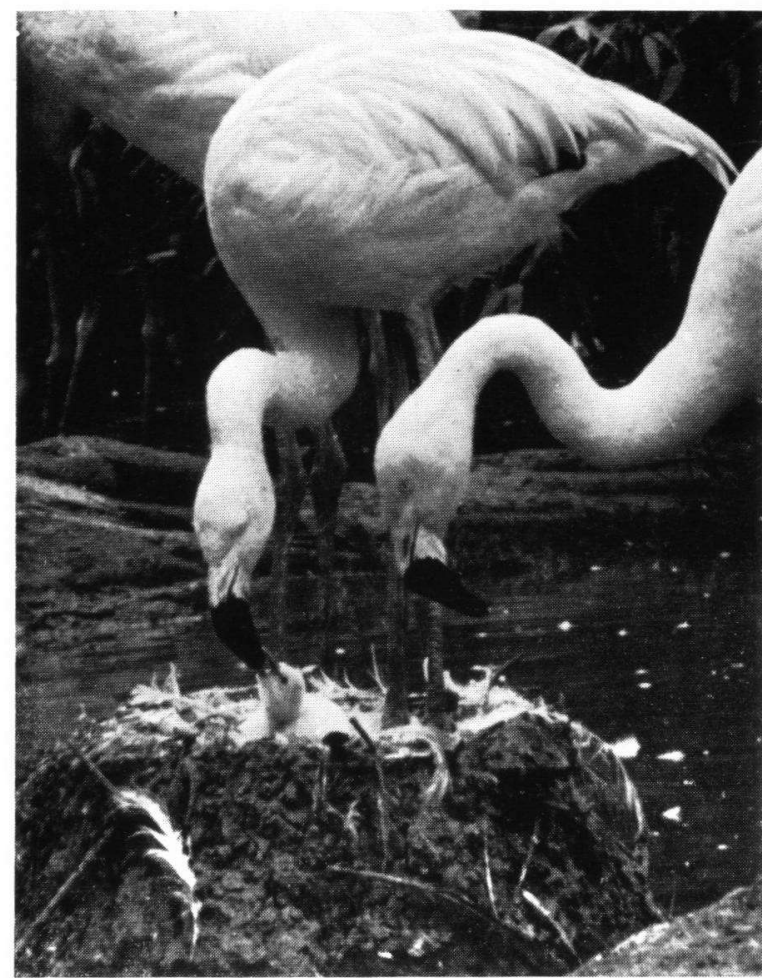

Phoenicopterus ruber chilensis.

Junges zwei Tage alt. Eltern füttern.

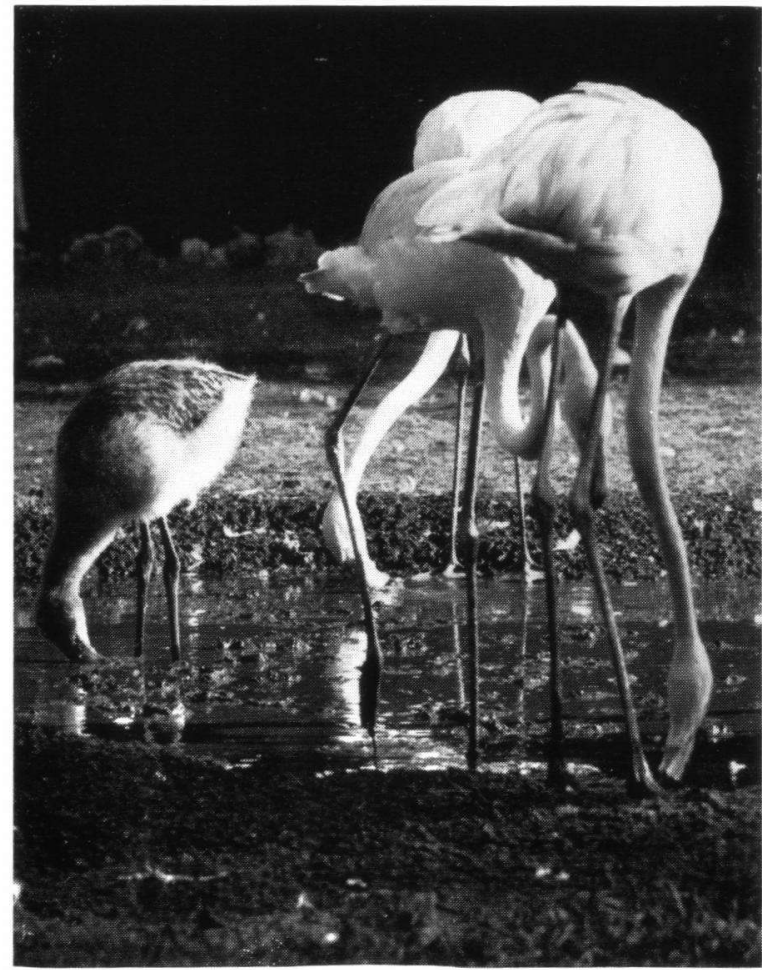

Phoenicopterus muber chilensis.

Junges ein Monat alt.

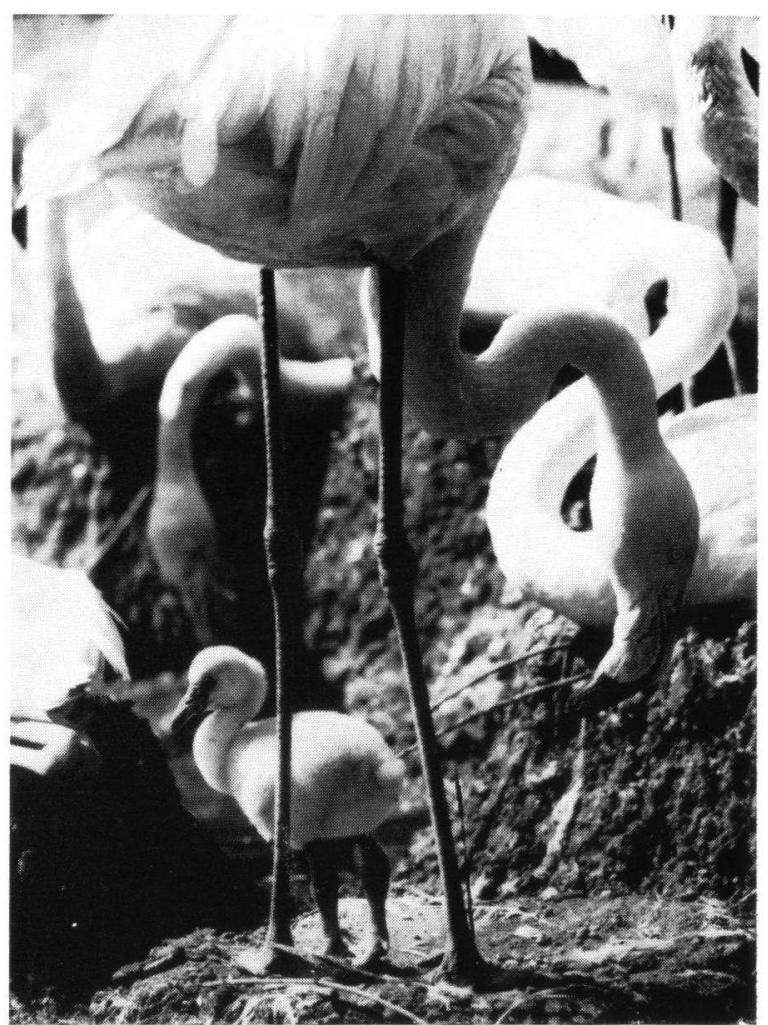

Phoenicopterus ruber roseus.

Junges ein Woche alt.

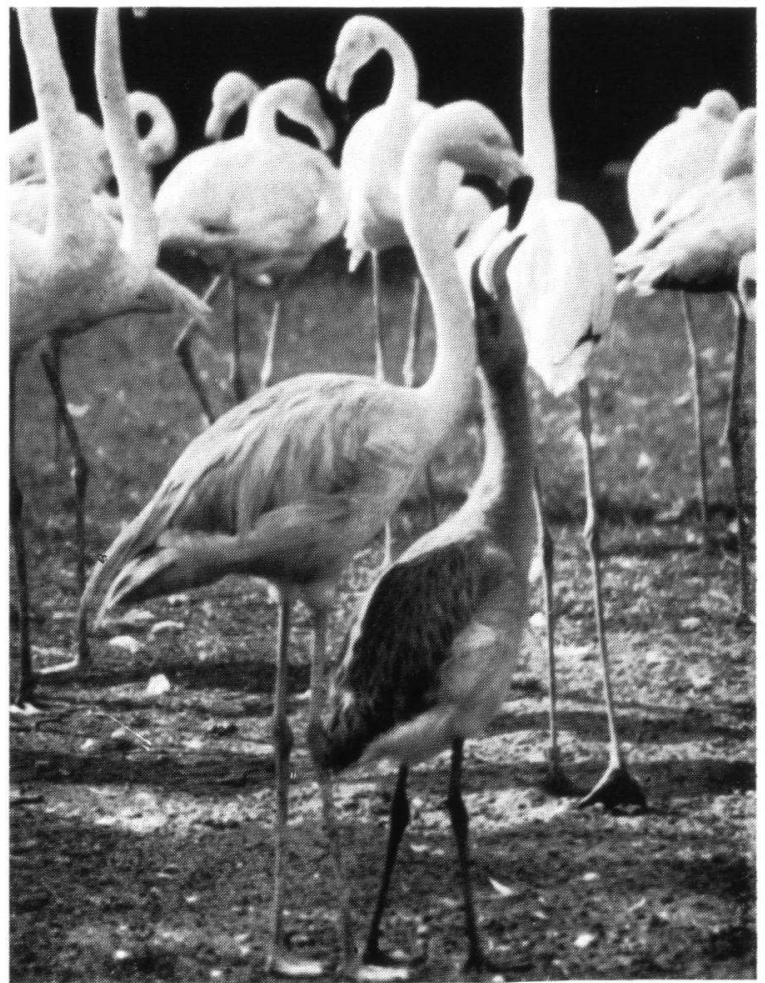

Phoenicopterus ruber chilensis.

Männchen füttert zehn Wochen altes Junges. 